\title{
ON AN INTEGRO-DIFFERENTIAL EQUATION OF ARBITRARY (FRACTIONAL) ORDERS WITH NONLOCAL INTEGRAL AND INFINITE-POINT BOUNDARY CONDITIONS
}

\section{H. El-Owaidy, A. M. A. El-Sayed And Reda Gamal Ahmed}

Abstract. In this paper, we study the existence and uniqueness of solutions for an integrodifferential equation of arbitrary (fractional) orders with nonlocal integral and infinite-point boundary conditions, continuous dependence of the solution on nonlocal data, on initial condition and on functional equation also will be study. An examples to prove main results.

Mathematics subject classification (2010): 26A33, 34B18, 34A30, 34K37, 34A08, 34B10.

Keywords and phrases: Functional equations, existence of solutions, continuous dependence, fractionalorder, boundary value problem, infinite point condition, Liouville-Caputo fractional derivative.

\section{REFERENCES}

[1] Ahmed El-Sayed And Reda Gamal, Infinite point and Riemann-Stieltjes integral conditions for an integro-differential equation, Nonlinear Analysis: Modelling and Control, 24, 5(2019), 733-754.

[2] Bingmei LiU, Junling Li, Lishan LiU AND YongQing WANG, Existence and uniqueness of nontrivial solutions to a system of fractional differential equations with Riemann-Stieltjes integral conditions, Advances in Difference Equations, 2018, 1(2018), 306.

[3] A. Boucherif, A First-Order Differential Inclusions with Nonlocal Initial Conditions, Applied Mathematics Letters. 63, 15 (2002), 409-414.

[4] A. Boucherif And Radu Precup, On The Nonlocal Initial Value Problem For First Order Differential Equations, Fixed Point Theory, 4, 2 (2003), 205-212.

[5] Dandan Min, Lishan Liu and Yonghong Wu, Uniqueness of positive solutions for the singular fractional differential equations involving integral boundary value conditions, Boundary Value Problems, 2018, 1 (2018), 23.

[6] J. Dugundu and A. Granas, Fixed Point Theory, Monografie Mathematyczne. PWN. Warsaw, 1982.

[7] H. El-Owaidy, A. M. A. El-Sayed And Reda Gamal Ahmed, Existence of solutions of a coupled system of functional integro-differential equations of arbitrary (fractional) orders, Malaya $\mathrm{J}$. Mat, 6, 4(2018), 774-780.

[8] A. M. A. El-Sayed And Reda Gamal Ahmed, Existence of Solutions for a Functional IntegroDifferential Equation with Infinite Point and Integral Conditions, International Journal of Applied and Computational Mathematics, 24, 4 (2019), 108.

[9] H. GAO AND X. HAN, Existence of positive solutions for fractional differential equation with nonlocal boundary condition, Int. J. Differ. Equ, 2011, (2011), 10 pages.

[10] K. Goebel And W. A. Kirk, Topics in Metric Fixed point theory, Cambirdge Universty Press, 1990.

[11] F. GE, H. ZHOU AND C. KOU, Existence of solutions for a coupled fractional differential equations with infinitely many points boundary conditions at resonance on an unbounded domain, Differ. Equ. Dyn. Syst, 24, (2016), 1-17.

[12] G. M. Guerekata, A Cauchy problem for some fractional abstract differential equation with non local conditions, Nonlinear Analysis, 70, (2009), 1873-1876.

[13] L. GUO, L. LIU AND Y. WU, Existence of positive solutions for singular fractional differential equations with infinite-point boundary conditions, Nonlinear Analysis: Modelling and Control, 21, (2016), 635-650. 
[14] S. HAMANI, M. BENCHORA AND J. R. GRAEF, Existence results for boundary-value problems with nonlinear fractional diffrential inclusions and integral conditions, EJQTDE, 20, (2010), 1-16.

[15] Hari M. SRivastava, Ahmed M. A. El-S Syed and Fatma M. GaAfar, A Class of Nonlinear Boundary Value Problems for an Arbitrary Fractional-Order Differential Equation with the RiemannStieltjes Functional Integral and Infinite-Point Boundary Conditions, Symmetry, 10, 10(2018), 508.

[16] HUSSEIN A. H. S ALEM, On the fractional order m-point boundary value problem in reflexive Banach spaces and weak topologies, Journal of Computational and Applied Mathematics, 224, 2 (2009), 565572.

[17] A. N. Kolomogorov And S. V. Fomin, Introductory real analysis, Dover Puble. Inc, 1975.

[18] I. Podlubny, Fractional differential equations, Academic Press, 1999.

[19] Q. ZhONG, X. ZHANG, Positive solution for higher-order singular infinite-point fractional differential equation with p-Laplacian, Adv. Differ. Equ, 2016:11, (2016).

[20] Xinqiu Zhang, Lishan Liu, Yonghong Wu and Yumei Zou, Fixed-Point Theorems for Systems of Operator Equations and Their Applications to the Fractional Differential Equations, Journal of Function Spaces, 2018, (2018).

[21] Xingiu Zhang, Lishan Liu, Yonghong Wu and Yumei Zou, Existence and uniqueness of solutions for systems of fractional differential equations with Riemann-Stieltjes integral boundary condition, Advances in Difference Equations, 2018, 1(2018), 204.

[22] Xiaoqian LiU, Lishan LiU and Yonghong Wu, Existence of positive solutions for a singular nonlinear fractional differential equation with integral boundary conditions involving fractional derivatives, Boundary Value Problems, 2018, 1(2018), 24. 